\title{
Intertemporal Market Risks and the Cross-Section of Greek Average Returns
}

\author{
Michail Koubouros ${ }^{1}$ \\ University of Peloponnese \\ Ekaterini Panopoulou ${ }^{2}$ \\ National University of Ireland \& University of Piraeus
}

This draft: September 18, 2005

\footnotetext{
${ }^{1}$ Corresponding author: University of Peloponnese, Department of Economics, Terma Karaiskaki, 22100 Tripolis, Greece. Phone: (+30) 2710 230129, fax: (+30) 2710230139 , e-mail: m.koubouros@uop.gr. We are grateful to Gikas Hardouvelis, Dimitrios Malliaropulos, Jack Meyer and participants at various seminars at the University of Peloponnese, the University of Piraeus and the National University of Ireland for helpful comments and suggestions. We acknowledge financial support from the Greek Ministry of Education and the European Union under "Pythagoras" grant. The usual disclaimer applies.

${ }^{2}$ Department of Banking and Financial Management, University of Piraeus, Greece and Department of Economics, National University of Ireland Maynooth, email: apano@nuim.ie.
} 


\begin{abstract}
This paper examines whether the overall market risk along with risks reflecting uncertainty related to the long run dynamics of market cash flows (dividends) and discount rates (returns) price average returns on single-sorted portfolios of the Greek stock market. Following Campbell and Vuolteenaho (American Economic Review, 2004) we check whether these two types of risk provide an empirical improvement over the static CAPM and if cash-flow risk is more important than discount-rate risk, as a rational I-CAPM risk story would predict. Our results suggest that the two-beta intertemporal model performs at least as well as the Fama-French (Journal of Financial Economics, 1993) three factor model since it explains half of the cross-sectional variation in average returns and delivers an economically and statistically acceptable estimate of the coefficient of relative risk aversion. More importantly, despite the relative importance of market discount-rate risk, it is market dividend-growth risk that turns out to be far more important in determining average returns on Greek portfolios.
\end{abstract}

JEL: G11, G12, G14

Keywords: CAPM, beta, cash flow risk, discount rate risk, risk aversion. 


\section{Introduction}

Numerous studies have shown that the single beta CAPM, at least in its unconditional form, performs poorly since the cross-sectional variation in unconditional market betas cannot match the observed spread in average excess returns. ${ }^{1}$ Recently, Campbell and Vuolteenaho (2004) and Campbell, Polk and Vuolteenaho (2005) show that the market beta can be decomposed into a relatively bad cash-flow beta, reflecting news about the market's future cash flows (dividend growth rates), and a relatively good discount-rate beta, reflecting news about the market's future discount rates (returns). According to their model the two parts of total market risk have different implications in asset pricing. Specifically, since market cash-flow shocks and discount-rate shocks represent permanent and temporary shocks to overall wealth respectively, rational conservative investors are particularly averse to the former and require a higher premium. More importantly, this cash-flow risk premium should be a multiple of their attitude toward risk. Empirically, Campbell and Vuolteenaho (2004) find that their decomposition could solve the small-value puzzle found in US data.

In this paper we study the cross-sectional behavior of cash-flow and discount-rate risks along with their ability to price returns for a set of 25 single sorted portfolios of the Greek stock market (Athens Stock Exchange, A.S.E.) for the period from 1991 to 2003. Using the empirical methodology of Campbell (1991), Campbell and Mei (1993), Campbell and Vuolteenaho (2004) and Campbell, Polk and Vuolteenaho (2005), we first estimate market cash-flow and discount-rate news and betas and then check whether the sensitivities of portfolio returns to these total market risk components can serve as sufficient risk measures which are priced in A.S.E. returns. Although some recent studies examine the properties of the two components of aggregate market return in several emerging markets (e.g. Phylaktis and Ravazzolo, 2002), there is no other study, to the best of our knowledge, which examines the asset pricing implications of this decomposition using A.S.E. data. In this respect, our study comes as a direct complement to these empirical findings since it provides some new insights, in terms of a small and emerging market, on the independent role of economic fundamentals in pricing the cross-section of average stock returns.

Our results indicate that the two-beta decomposition of the total market risk increases the ability of the static, single factor, CAPM to price Greek stock returns. More in detail, all portfolios exhibit considerable spread in risk exposure to market

\footnotetext{
${ }^{1}$ For a recent review on the CAPM literature see, among others, Fama and French (2004).
} 
cash-flow and discount-rate risk and both types of risk are cross-sectionally priced. Furthermore, by employing a discrete-time intertemporal asset pricing model, we find that cash-flow risk is more important for the cross-section of average A.S.E. returns since it embodies a beta-risk premium that is much higher than the one embodied in discount-rate risk. Specifically, the two-beta model captures almost half of the variation in portfolio mean returns, performs slightly better than the popular Fama-French (1993) model and delivers meaningful and highly significant values of risk aversion. Overall, and in line with the US findings of Campbell and Vuolteenaho (2004) and Campbell, Polk and Vuolteenaho (2005), the two-beta model explains the spread in returns found across value and size portfolios and thus provides valuable insights for the small-over-large and value-over-growth puzzles.

The remainder of the paper is organized as follows: Section 2 provides the theoretical decomposition of total market risk into two parts; return risks associated with market's cash-flow and discount-rate dynamics. It also develops the intertemporal asset pricing framework that will be used for the asset pricing estimation. The dataset and the econometric methodology employed to extract the news components of market unexpected returns are given in Section 3. Section 4 presents the empirical results and, finally, Section 5 offers some concluding remarks.

\section{The Model}

Agents are assumed to choose their optimal consumption and portfolio positions using the recursive utility framework provided by Epstein and Zin $(1989,1991)$ and Weil (1989). The lifetime utility function of the investor is given by the recursive utility function $U_{t}$, defined over current real consumption, $C_{t}$, and future expected utility of real consumption, $E_{t}\left(U_{t+1}\right)$ :

$$
U_{t}\left[C_{t}, E_{t}\left(U_{t+1}\right)\right]=\left[(1-\delta) C_{t}^{\frac{1-\gamma}{\theta}}+\delta E_{t}\left(U_{t+1}^{1-\gamma}\right)^{\frac{1}{\theta}}\right]^{\frac{\theta}{1-\gamma}}
$$

where $0<\delta<1$ is the subjective discount factor, $\gamma>0$ is the constant, under this specification, coefficient of relative risk aversion (CRRA), $\theta$ is a parameter defined as $\theta=(1-\gamma) /\left(1-\frac{1}{\sigma}\right)$, and $\sigma>0$ is the elasticity of intertemporal substitution (EIS) between current and expected future consumption. Equation (1) has the advantage of breaking the tight link between CRRA and EIS given by power utility $\left(\gamma=\frac{1}{\sigma}\right)$, 
thus, disconnecting investors' risk attitude across states of nature (described by $\gamma$ ) and across time (described by $\sigma$ ).

The consumer is assumed to finance all her consumption plan entirely from her total real wealth $W_{t}$, given the following dynamic budget constraint:

$$
W_{t+1}=\left(1+R_{W, t+1}\right)\left(W_{t}-C_{t}\right)
$$

where $R_{W, t+1}$ is the net real return on total wealth. Epstein and Zin (1989) solve for the optimal portfolio and consumption policies and show that the following set of conditional moment restrictions hold for each asset $i$ and the total-wealth portfolio $W$ :

$$
E_{t}\left[\beta^{\theta} G^{-\frac{\theta}{\sigma}} R_{W, t+1}^{\theta-1} R_{i, t+1}\right]=1 ; \text { for } i=1, \ldots, N
$$

where $G_{t+1} \stackrel{\text { def }}{=} \frac{C_{t+1}}{C_{t}}$ is the optimally chosen gross growth rate of real consumption between $t$ and $t+1$. The above set of non-linear moment restrictions can be linearized using the assumption of joint conditional log-normality of asset returns and consumption in the spirit of Hansen and Singleton (1983). Using these strong assumptions along with the dynamic budget constraint in (2), Campbell $(1993,1996)$ derives the following cross-sectional linear restrictions on assets' risk premia that places no role in consumption as a priced risk factor:

$$
E_{t}\left[R_{i, t+1}^{e}\right]=\gamma \operatorname{Cov}_{t}\left(r_{i, t+1}, r_{W, t+1}-E_{t}\left[r_{W, t+1}\right]\right)+(1-\gamma) \operatorname{Cov}_{t}\left(r_{i, t+1},-N_{W, t+1}^{D R}\right),
$$

where $E_{t}\left[R_{i, t+1}^{e}\right]=E_{t}\left[R_{i, t+1}\right]-R_{f, t+1}$, and $R_{f, t+1}$ is the simple return on the risk-free asset. The above equation can be viewed as a discrete-time version of Merton's (1973) I-CAPM where changes in the future investment opportunity sets (captured by news about future total wealth portfolio returns, $N_{W, t+1}^{D R}$ ) are also priced in addition to the contemporaneous market risk (the first covariance term).

Campbell and Vuolteenaho (2004) go one step further and using the unexpected return decomposition developed by Campbell and Shiller (1988a) and further extended by Campbell (1991) break the first factor (market innovation) into news about future dividend (cash-flows) growth rates and returns (discount-rates). Formally, Campbell (1991) has derived the following approximate log linear decomposition of returns into time $t+1$ revision in expectations (news) about the present value of all future totalwealth dividend growth rates (cash-flow news, $N_{W}^{C F}$ ) and the time $t+1$ revision in expectations about the present value of all future total-wealth returns (discount-rate 
news, $\left.N_{W}^{D R}\right)$ :

$$
r_{W, t+1}-E_{t+1}\left[r_{W, t+1}\right]=N_{W, t+1}^{C F}-N_{W, t+1}^{D R},
$$

where $N_{W, t+1}^{C F}=E_{t+1}\left[\sum_{j=0}^{\infty} \rho^{j} \Delta d_{W, t+1+j}\right]-E_{t}\left[\sum_{j=0}^{\infty} \rho^{j} \Delta d_{W, t+1+j}\right]$ and

$N_{m, t+1}^{D R}=E_{t+1}\left[\sum_{j=1}^{\infty} \rho^{j} r_{W, t+1+j}\right]-E_{t}\left[\sum_{j=1}^{\infty} \rho^{j} r_{W, t+1+j}\right], P_{W t+1}$ is the real aggregate (market) stock price measured at the end of period $t+1$ (ex-dividend), $d_{W, t+1}=\log \left(D_{W, t+1}\right)$ is the $\log$ of the real dividend payment to total wealth during this period,

$r_{W, t+1}=\log \left(\frac{P_{W, t+1}+D_{W, t+1}}{P_{W, t}}\right)$ is the one-period holding log real gross return on the total wealth portfolio, $\rho_{W}=1 /[1+\exp (W)]$ and $\overline{\delta_{W}}=E\left[\log \left(d_{W, t}-p_{W, t}\right)\right]$ is the unconditional mean of the log aggregate dividend-price ratio. The first term in (5) is the time $t+1$ revision in dividend growth expectations and represents a permanent positive effect on total wealth since it is never reversed subsequently, whereas the second one is the time $t+1$ revision in expectations about future returns on total wealth and thus can be viewed as a temporary shock to the total wealth since the unexpected capital gain today $\left(r_{W, t+1}-E_{t+1}\left[r_{W, t+1}\right]>0\right)$ is at a cost of lower future investment opportunities, i.e. $E_{t+1}\left[\sum_{j=1}^{\infty} \rho^{j} r_{W, t+1+j}\right]-E_{t}\left[\sum_{j=1}^{\infty} \rho^{j} r_{W, t+1+j}\right]<0$.

Using the above decomposition of the total wealth unexpected return and the two factor asset pricing restriction in (4) we get the following asset pricing model that assigns different roles for aggregate dividend growth rates' news and returns' news in determining asset risk premia:

$$
E_{t}\left[R_{i, t+1}^{e}\right]=\gamma \operatorname{Cov}_{t}\left(r_{i, t+1}, N_{W, t+1}^{C F}\right)+\operatorname{Cov}_{t}\left(r_{i, t+1},-N_{W, t+1}^{D R}\right),
$$

The covariance risk premium representation in (6) can have an equivalent beta-like premium representation (Cochrane, 2001). Multiplying and dividing by the variance of total-wealth return innovations, $\operatorname{Var}_{t}\left(r_{W, t+1}-E_{t}\left[r_{W, t+1}\right]\right)$, we get:

$$
E_{t}\left[R_{i, t+1}^{e}\right]=\lambda_{C F, t} \beta_{i, C F, t}+\lambda_{D R, t} \beta_{i, D R, t}
$$

with $\lambda_{C F, t}=\gamma \operatorname{Var}_{t}\left(r_{W, t+1}-E_{t}\left[r_{W, t+1}\right]\right), \lambda_{D R, t}=\operatorname{Var}_{t}\left(r_{W, t+1}-E_{t}\left[r_{W, t+1}\right]\right)$ and:

$$
\begin{aligned}
\beta_{i, W, t} & =\frac{\operatorname{Cov}_{t}\left(r_{i, t+1}, N_{W, t+1}^{C F}\right)}{\operatorname{Var}_{t}\left(r_{W, t+1}-E_{t}\left[r_{W, t+1}\right]\right)}+\frac{\operatorname{Cov}_{t}\left(r_{i, t+1},-N_{W, t+1}^{D R}\right)}{\operatorname{Var}_{t}\left(r_{W, t+1}-E_{t}\left[r_{W, t+1}\right]\right)} \\
& =\beta_{i, C F, t}+\beta_{i, D R, t}
\end{aligned}
$$


Equation (8) states that the required risk premium on asset $i$ is jointly determined by the betas of its return with the corresponding decomposed components of the total market risk; cash-flow and discount-rate beta that add to the full total wealth, CAPM, beta. A conservative risk-averse investor $(\gamma>1)$ demands a higher risk price for risks associated with total-wealth cash-flow (dividend growth) uncertainty $\left(\beta_{i, C F}\right)$ rather than for risks linked to shocks to total wealth portfolio returns $\left(\beta_{i, D R, t}\right)$, since any positive (negative) shock to wealth discount rates is at a benefit (cost) of worse future investment opportunities, whereas the investor is never compensated later for every positive (negative) shock to dividends. Hence, the beta price of market cash-flow risk $\lambda_{C F}$ is a $\gamma$ multiple of the beta risk prices of market discount-rate risk $\lambda_{D R}$. Thus, for a conservative investor it must be $\lambda_{C F}>\lambda_{D R}>0$.

In order to get comparable results to the empirical literature of the unconditional CAPM and, more importantly, to the empirical findings of the two-beta model of Campbell and Vuolteenaho (2004) that places a relatively more important role in cash-flow risk, we condition down equation (7) and proceed with its unconditional version.

\section{Data and Empirical Methodology}

Our study is based on monthly Greek asset and macroeconomic data for the period from June 1991 to May 2003 (133 monthly observations) obtained from the Datastream International database. Specifically, our data consist of different sets of common stock portfolios sorted on various firm specific characteristics and risk measures and a set of economy-wide variables that serve as instruments. Following the common practice, these variables have been selected under the assumption that they forecast future returns. Lastly, we assume that the market (value-weighted) portfolio is a good proxy for the total-wealth portfolio in the Greek economy, so that $R_{W}=R_{M}$.

We employ a variant of the Fama and French (1993) methodology to construct value-weighted returns on 25 firm-characteristic single-sorted portfolios on book-tomarket, dividend-yield, size, price-earnings and 3-month momentum, and the two size and book-to-market factor mimicking portfolios, Small-Minus-Big $(S M B)$ and High-Minus-Low $(H M L)$, respectively. The latter factor mimicking portfolios will be used as a benchmark in our asset pricing tests. In June, every year, we first break the full menu of A.S.E. common stocks available into 5 groups (based on accounting 
information) each containing an equal number of stocks and second, we compute the simple market capitalization weighted-average monthly holding period return for each of the 5 portfolios for the following year using monthly closing prices. The annual dividend paid on each stock is divided by 12 and added to the monthly closing price, so that our returns include dividends. The procedure is repeated every year and we end up with time-series data of simple returns on each characteristics-sorted portfolio. Although the model in (7) is written in real log returns, we assume that for the monthly test interval we employ, inflation rates are almost fully forecastable, and thus we proxy real log returns with nominal log returns.

The aggregate value mimicking factor portfolio $H M L$ was created using the 40-2040 rule employed by Fama and French (1993). However, for the $S M B$ portfolio, we adjust the formation mechanism to account for peculiarities of the Greek data. We use the 70th quantile of the market value instead of the median that was used by Fama and French. Using a larger breakpoint we can create a distribution of the market value similar to that of Fama and French, while the small capitalization portfolio represents on average the $8 \%$ of the total A.S.E. market. At the end of June of each year, we create the size and book-to-market double-sorted portfolios of Fama and French (1993) ( $S L, S M, S H, B L, B M$ and $B H)$ and calculate the value-weighted monthly returns for the next 6 months. Then, the aggregate book-to-market and size portfolios are defined as $H M L=(S H+B H) / 2-(S L+B L) / 2$ and $S M B=$ $(S L+S M+S H) / 3-(B L+B M+B H) / 3$ respectively.

The second set used in our analysis consists of variables that have proven successful in predicting the future state of the economy and asset returns. The innovations of these variables are used to generate cash-flow and discount-rate news through a $\operatorname{VAR}(1)$ specification. More in detail, we use: (a) the monthly log difference of the OECD leading indicator, $\Delta \log (L I)$, (b) the market log price-earnings ratio, $p-e$, and (c) the small-stock value spread, $V S$, defined as the difference between the $\log (\mathrm{B} / \mathrm{M})$ of the small high-B/M portfolio and the $\log (\mathrm{B} / \mathrm{M})$ of the small low-BE/ME portfolio. ${ }^{2}$

The asset pricing model in (7) uses cash-flow and discount-rate news as priced factors. We follow Campbell (1991) and we estimate them using a first-order vector autoregressive, $\operatorname{VAR}(1)$, model. We first estimate expected returns and the revisions

\footnotetext{
${ }^{2}$ Recently, the value spread $V S$ variable has been found to be a good forecaster of US returns. See, among others, Campbell and Vuolteenaho (2004), Campbell, Polk and Vuolteenaho (2005) and Koubouros, Malliaropulos and Panopoulou (2005). Following this evidence we use the value spread as a predictor of A.S.E. returns.
} 
in expectations about future returns $\left(E_{t}\left[r_{M, t+1}\right]\right.$ and $\left(E_{t+1}-E_{t}\right) \sum_{j=1}^{\infty} \rho_{M}^{j} r_{M, t+1+j}$, respectively) and then we use $r_{M, t+1}$ and equation (5) to back out the market cashflow news. This practice has an important advantage as it relies only on the dynamics of expected returns and there is no need for modelling the dynamics of dividends since the latter are derived by the VAR estimates and the realizations of returns and state variables.

We assume that the data are generated by the following $\operatorname{VAR}(1)$ model:

$$
y_{t+1}=\Gamma+A y_{t}+u_{t+1}
$$

where $y_{t+1}=\left(r_{m, t+1}, y_{1, t+1}, \ldots, y_{m, t+1}\right)$ is a $m \times 1$ vector of variables containing returns as its first element and $(m-1)$ variables which have predictive power for returns, $\Gamma$ is a $m \times 1$ vector of constants and $A$ is a $m \times m$ matrix of constants. We estimate (9) for the market return and then compute cash-flow and discount-rate news as linear functions of the $t+1$ vector of innovations, $u_{t+1}$ :

$$
N_{M, t+1}^{D R}=e 1^{\prime} \lambda u_{t+1} \quad N_{M, t+1}^{C F}=\left(e 1^{\prime}+e 1^{\prime} \lambda\right) u_{t+1},
$$

where $e 1$ is a $m \times 1$ vector with the first element equal to unity and the remaining elements equal to zero. The mapping of the shock vector to the news vectors is given by $\lambda \equiv \rho A\left(I_{m}-\rho A\right)^{-1} \cdot e 1^{\prime} \lambda$ captures the long-run significance of each individual $\operatorname{VAR}(1)$ shock to discount-rate expectations. The greater the absolute value of a variables coefficient in the return prediction equation (the top row of $A$ ), the greater the weight the variable receives in the discount-rate-news formula (10). Also, more persistent variables should also receive more weight, which is captured by the term $\left(I_{m}-\rho A\right)^{-1}$.

\section{Empirical Evidence}

\subsection{Estimation of Cash-Flow and Discount-Rate News and Betas}

Table 1 reports parameter estimates for the market $\operatorname{VAR}(1)$ model. Our estimates suggest that the state variables have some predictive power for stock market excess returns (adj.- $R^{2}$ of $9.5 \%$ ). Specifically, monthly market returns display some degree 
of mean reversion as depicted in the statistically significant autoregressive coefficient of 0.147 . The effect of the log change of the OECD Leading Indicator, $\Delta \log (L I)$, on market returns is positive, a finding consistent with the positive relationship of output growth and stock market returns. The remaining state variables, namely the log priceto-earnings ratio $(p-e)$ and the small-stock value spread $(V S)$, positively predict the market return. Our findings are in contrast with findings in previous research (see, e.g. Campbell and Shiller, 1988a, 1988b, 1998, Rozeff, 1984, Fama and French, 1988, 1989, Eleswarapu and Reinganum, 2004 and Brennan, Wang and Xia, 2004). The remaining columns of Table 1 summarize the dynamics of the state variables. The growth of the OECD Leading Indicator process is positively autocorrelated with a coefficient of 0.528 , while both the $p-e$ and the $V S$ display an increased degree of persistence as suggested by a coefficient estimate of 0.97 . This persistence does not induce any estimation problems as no instability is apparent at the $\operatorname{VAR}(1)$ residuals. Moreover, the last rows of Table 1 report the ARCH-LM tests for heteroskedasticity in the VAR(1) residuals, which do not suggest any second-order dependence in the error terms.

Table 2 summarizes the behavior of implied (from the VAR(1) specification) cashflow news $\left(N_{M, t+1}^{C F}\right)$ and discount-rate news $\left(N_{M, t+1}^{D R}\right)$ components of market returns. The top panel shows that the standard deviation of discount-rate news is more than twice the standard deviation of cash-flow news. This finding is consistent with Campbell (1991) and Campbell and Vuolteenaho (2004). However, in contrast to Campbell and Vuolteenaho (2004), but in line with Campbell (1991 and 1996), the two components of return exhibit some degree of correlation, 0.563. In what follows, we use discount-rate neutral cash-flow news resulting from regressing market cash-flow news on discount-rate news and keeping the estimated constant plus the residuals, in order to examine the independent ability of the two in pricing average returns.

The bottom panel of Table 2 reports correlations of cash-flow and discount-rate news with innovations in market excess returns and state variables. Discount-rate and cash-flow news are negatively correlated with innovations in the market return and the price-earnings, respectively. In contrast, innovations to the value spread are strongly positively correlated with discount-rate and cash-flow news.

Empirical measures of the cash-flow and discount-rate betas in (8) are derived using a methodology similar to this employed in Campbell and Vuolteenaho (2004) to ensure that our sample estimates are not affected by non-synchronous trading (see, for 
example, Scholes and Williams, 1977 and Dimson, 1979) and under-reaction of stock prices to changes in the market index, especially for large stocks (see, for example, McQueen, Pinegar and Thorly, 1996 and Peterson and Sanger, 1995). Our two sample betas, which will be used in the cross-sectional regression analysis, are defined as the sum of contemporaneous, one lag and two lag full-sample covariances of portfolio returns at $t+1$ with market news, divided by the full-sample variance of the market return innovations, $\operatorname{Var}\left(r_{M, t+1}-E_{t}\left[r_{M, t+1}\right]\right)$. As a result, the beta components of the full market beta (cash-flow news' beta $\widehat{\beta}_{i, C F}$ and discount-rate news' beta $\widehat{\beta}_{i, D R}$ ) are estimated as follows:

$$
\widehat{\beta}_{i, C F(\text { or }-D R)}=\sum_{k=0}^{2} \frac{\widehat{\operatorname{Cov}}\left(r_{i, t+1}, N_{M, t+1-k}^{C F(\text { or }-D R)}\right)}{\widehat{\operatorname{Var}}\left(r_{M, t+1}-E_{t}\left[r_{M, t+1}\right]\right)}
$$

The popular three-factor Fama-French (1993) asset pricing model is used a benchmark. In order to keep the comparison of the results of this asset pricing model in line with the two-beta asset pricing model, we estimate betas with the aggregate size and value factor mimicking portfolios $\left(\widehat{\beta}_{i, S M B}\right.$ and $\widehat{\beta}_{i, H M L}$ respectively) with two lags in the covariance term as follows (11):

$$
\widehat{\beta}_{i, p}=\sum_{k=0}^{2} \frac{\widehat{\operatorname{Cov}}\left(r_{i, t+1}, r_{p, t+1-k}\right)}{\widehat{\operatorname{Var}}\left(r_{p, t+1}-E_{t}\left[r_{p, t+1}\right]\right)}, \text { for } p=r_{S M B}, r_{H M L}, r_{M}
$$

Table 3 reports the summary statistics of the (annualized) returns of the 25 portfolios and the market, cash-flow, discount-rate, $H M L$ and $S M B$ betas. The average annualized return on the market portfolio is $9.85 \%$ with a standard deviation of $3.1 \%$. The autocorrelation of the return is diminishing with the lag length, even turning negative for horizons of 9-12 months. Our data set reveals an average annual value premium of $7.48 \%$ and an average annual size premium of $25.19 \%$. Similarly, high dividend-yield, low price-earnings and 3-month momentum portfolios yield an average annual premium of $7.49 \%, 14.27 \%$ and $14.77 \%$, over the low dividend-yield, high price-earnings and 3-month losers' portfolios, respectively. The considerable spread in average returns provides a challenge to traditional asset pricing theory since it should be matched with an equivalent spread in aggregate risk exposure.

Table 4 reports the estimated betas given by our definition in (11) along with their respective standard errors. ${ }^{3}$ The main characteristic of our results is that our

\footnotetext{
${ }^{3}$ Those beta coefficients and their related standard errors were obtained by regressing the relevant
} 
methodology generates considerable spread in the overall market risk $\beta_{i, M}$ (the sum of individual cash-flow and discount-rate betas defined in (8) especially for the value and size portfolios. This fact may be consistent with the static CAPM that states that overall market risk (beta) can be sufficient to capture differences in the crosssection of expected returns. The observed spread in the two aggregate bad (cash-flow) and good (discount-rate) betas confirm the story argued by Campbell and Vuolteenaho (2004) and Campbell, Polk and Vuolteenaho (2005) that value stocks (high B/M) have relatively high cash-flow betas while growth stocks have relatively high discount-rates betas. More importantly, both components of total market risk increase with value and decrease with size indicating that both are important for the relative riskiness of value-growth and small-large portfolios, respectively. Lastly, all portfolios exhibit considerable spread in their return exposure to aggregate size and distress risk as captured by $S M B$ and $H M L$ betas, indicating that the three-factor Fama-French (1993) model could be an alternative to the CAPM. However, and since the two factor portfolios do not mimic clear fundamental (economy-wide) sources of risk, we will use this model as a practical tool for comparison purposes.

\subsection{Are Cash-Flow and Discount-Rate Risks Individually Priced?}

Having estimated the full-sample cash-flow and discount-rate betas given our specification of the return generating processes in (9) we proceed with cross-sectional asset pricing tests to evaluate the ability of our two-beta model to capture cross-sectional variation in A.S.E. average portfolio returns. Since, we are interested in examining the cross-sectional behavior of risk and return we follow Campbell and Vuolteenaho (2004) and study the unconditional version of the asset pricing model in (7). However, and given the low quality of risk-free rate data for our sample period we proceed with the zero-beta versions of our asset pricing tests. So, the constant term $\lambda_{0}$ in the linear specifications below is no longer the average pricing error as it would be in (4), (6) and (7), and thus, it can (or better should, under the hypothesis of the existence of a zero-beta asset in A.S.E.) be different from zero. The model is tested against the static CAPM and the Fama-French (1993) three-factor.

More specifically, we consider the following cross-sectional specification of the two

components and adjusting for the disparity caused by the modified variance. For example, if we want to estimate $\beta_{i, C F}$ as given by (11), we run the regression of $r_{i, t+1}$ on $N_{M, t+1}^{C F}\left[\operatorname{Var}\left(r_{M, t+1}-\right.\right.$ $\left.\left.E_{t}\left[r_{M, t+1}\right]\right) / \operatorname{Var}\left(N_{M, t+1}^{C F}\right)\right]$ as well as the two lag terms. 
(cash-flow and discount-rate) beta model:

$$
E_{T}\left[R_{i}\right]=\lambda_{0}+\lambda_{C F} \widehat{\beta}_{i, C F}+\lambda_{D R} \widehat{\beta}_{i, D R}
$$

and we test this two-beta specification against the popular static single-beta CAPM that imposes the same risk prices in cash-flow and discount-rate risk and thus prices aggregate market risk, $\beta_{i, M}$ :

$$
E_{T}\left[R_{i}\right]=\lambda_{0}+\lambda_{M} \widehat{\beta}_{i, M},
$$

and the popular three-factor Fama-French (1993) model that adds aggregate value $(H M L)$ and size $(S M B)$ factor mimicking portfolios as competing factors to the aggregate market return:

$$
E_{T}\left[R_{i}\right]=\lambda_{0}+\lambda_{m} \widehat{\beta}_{i, M}+\lambda_{H M L} \widehat{\beta}_{i, H M L}+\lambda_{S M B} \widehat{\beta}_{i, S M B},
$$

In all equations $E_{T}\left[R_{i}\right]$ denotes average (sample mean) portfolio returns and $\widehat{\beta}_{i, k}$ denote the estimated betas on the $k^{\text {th }}$ factor as defined in (11) and (12). We estimate the unconditional unrestricted prices of beta risks $\left(\widehat{\lambda}_{\mathrm{s}}\right)$ for the aforementioned models as well as the following restricted version of the two-beta model in (16):

$$
E_{T}\left[R_{i}\right]=\lambda_{0}+\gamma \lambda \widehat{\beta}_{i, C F}+\lambda \widehat{\beta}_{i, C F}
$$

This last version enables to estimate the coefficient of relative risk aversion $\gamma$ and the risk premium on the discount-rate factor $\lambda$. The model predicts that the premium associated with market cash-flow risk must be a $\gamma$ multiple of the premium associated with discount-rate risk. For a conservative risk-averse investor $(\gamma>1$ in $(1)), \lambda_{C F}$ must be greater than $\lambda_{D R}$, i.e. $\lambda_{C F}>\lambda_{D R}$.

Table 5 presents the empirical findings of the cross-sectional asset pricing tests. The table reports the mean and standard error for each estimate, as well as the average adj.- $R^{2}$ of the regression. Figures 1 to 4 give a visual illustration of the empirical ability of the alternative models by plotting the realized and fitted average returns. The better the model performs the closest to the 45-degree line the points fall. A perfect match $\left(R^{2}=100 \%\right)$ is achieved when all points fall on the 45-degree line.

Contrary to many US studies (e.g. Fama and French, 1992, Campbell, Polk and Vuolteenaho, 2004), the traditional static CAPM performs quite well and explains 
almost half of the cross-sectional variation in average returns. However, it fails to produce a significant estimate for the zero-beta coefficient $\left(\widehat{\lambda}_{0}=-0.005\right.$ with s.e. $=$ $0.0048)$.

Next, we check whether the two-beta decomposition in (13) with unrestricted prices of beta risk can improve the empirical validity of the standard static CAPM and whether there are different roles in market cash-flow and discount-rate risks. The model performs quite well and generates statistically significant premia and explains $46.6 \%$ of the observed cross-sectional variation in A.S.E. portfolio returns. More importantly, it generates significant risk premia for both types of risk with the premium associated with market cash-flow risk being much higher than that associated with market's discount-rate risk $\left(\widehat{\lambda}_{C F}=0.0274\right.$ and $\left.\widehat{\lambda}_{D R}=0.0096\right)$. These results are in line with Campbell and Vuolteenaho (2004) and in favor of the total market risk decomposition in (7) and (8). Further, when we estimate the restricted version of the model in (16) the factor of proportionality, which is restricted to be equal to the coefficient of relative risk aversion, $\gamma$, is both economically and statistically significant. Specifically, the estimate of $\widehat{\gamma}=2.8572$ (s.e. $=0.1612)$ is in the range hypothesized by Mehra and Prescott (1985). We also tested for unconstrained risk premia using cash-flow and discount-rate risk once at a time (see, columns labelled CF and DR). Again, our results indicate that, although both types of intertemporal market risks are needed to describe the crosssection of returns, cash-flow risk is much more important with a risk premium three times higher than the one of discount-rate risk. The respective estimates are $\widehat{\lambda}_{C F}=$ 0.0320 and $\widehat{\lambda}_{D R}=0.0107$. The two Fama-French (1993) factors, $H M L$ and $S M B$, also perform relatively well by explaining the same proportion of cross-sectional volatility as the two-beta model, but fail to deliver statistically significant premia for the overall market risk. What is more, none of the aggregate value and size premia $\left(\lambda_{H M L}\right.$ and $\left.\lambda_{S M B}\right)$ are significant at the $1 \%$ level. Lastly, and for experimental purposes we use all factors in an extended model. Our results suggest that the relative importance of cash-flow risk is clear but we are inconclusive on the one of the discount-rate risk, especially when the significant size risk is included.

\section{Conclusions}

This paper builds on the decomposition of the overall market, or CAPM, risk into parts reflecting time variation related to the dynamics of aggregate market cash flows and 
discount rates using data from the small and emerging Greek stock market (Athens Stock Exchange). Employing the methodology of Campbell (1991), Campbell and Mei (1993) and Campbell and Vuolteenaho (2004) we decompose market betas into two sub-betas, associated with revisions in expectations about future market dividend growth rates and future returns. Using a VAR(1) approach and a discrete time version of Merton's I-CAPM, we test whether these components of overall market risk are rationally priced and thus explain the value, size and momentum premia observed in our monthly 1991-2003 sample. The theoretical model predicts that although both types of risk are important for the cross-section, market cash-flow risk (captured by the sensitivity of returns to market cash-flow news) should earn a higher beta-risk premium than market discount-rate risk.

The two-beta model performs quite well in pricing average returns on single-sorted portfolios according to book-to-market, dividend-yield, market capitalization, priceearnings and 3-month momentum. Consistent with theory, the model delivers an economically and statistically significant estimate of the coefficient of relative risk aversion (close to 3), explains almost half of the cross-sectional variation in A.S.E. portfolio returns and generally performs at least as good as the popular three-factor Fama-French (1993) model. We find that the exposure of Greek stock portfolios to risks associated with permanent shocks to aggregate market value (captured by market cash-flow risk) is compensated with higher unconditional risk prices than the exposure to risks associated with future market returns. Our results are in favor of a rational risk I-CAPM-type story where economic agents have a long-term optimizing behavior, do not behave myopically and value stocks according to their long-run riskiness. 


\section{References}

[1] Brennan Michael, Ashley Wang and Yihong Xia (2004), Estimation and test of a simple model of intertemporal asset pricing, Journal of Finance 59, 1743-1775.

[2] Campbell, John (1991), A variance decomposition of stock returns, Economic Journal 101, 157-159.

[3] Campbell, John (1993), Intertemporal asset pricing without consumption data, American Economic Review 83, 487-512.

[4] Campbell, John (1996), Understanding risk and return, Journal of Political Economy 104, 298-345.

[5] Campbell, John and Jiapping Mei (1993), Where do betas come from? Asset pricing dynamics and the sources of systematic risk, Review of Financial Studies, $6,567-592$.

[6] Campbell, John, Christofer Polk and Tuomo Vuolteenaho (2005), Growth or glamour? Fundamentals and systematic risk in stock returns, NBER Working Paper No. 11389.

[7] Campbell, John and Robert Shiller (1988a), The dividend-price ratio and expectations about future dividends and discount factors, Review of Financial Studies $1,195-228$

[8] Campbell, John and Robert Shiller (1988b), Stock prices, earnings and expected dividends, Journal of Finance, 43, 661-676.

[9] Campbell, John and Robert Shiller (1998), Valuation ratios and the long-run stock market outlook, Journal of Portfolio Management 24 (2), 11-26.

[10] Campbell, John and Tuomo Vuolteenaho (2004), Bad beta, good beta, American Economic Review 94, 1249-1275.

[11] Cochrane, John (2001), Asset Pricing, Princeton University Press, Princeton NJ.

[12] Dimson, Elroy (1979), Risk measurement when shares are subject to infrequent trading, Journal of Financial Economics 7, 197-226.

[13] Eleswarapu, Venkat and Marc Reinganum (2004), The predictability of aggregate stock market returns: evidence based on glamour stocks, Journal of Business $77(2), 275-294$.

[14] Epstein, Lawrence and Stanley Zin (1989), Substitution, risk aversion and the temporal behavior of consumption and asset returns: a theoretical framework, Econometrica 57, 937-969. 
[15] Epstein, Lawrence and Stanley Zin (1991), Substitution, risk aversion and the temporal behavior of consumption and asset returns: an empirical investigation, Journal of Political Economy 99, 263-286.

[16] Fama, Eugene and Kenneth French (1988), Dividend yields and expected stock returns, Journal of Financial Economics 22, 3-27.

[17] Fama, Eugene and Kenneth French (1989), Business conditions and expected returns on stocks and bonds, Journal of Financial Economics 25, 23-49.

[18] Fama, Eugene and Kenneth French (1992), The cross-section of expected stock returns, Journal of Finance 2, 427-465.

[19] Fama, Eugene and Kenneth French (1993), Common risk factors in the returns on stocks and bonds, Journal of Financial Economics 33, 3-56.

[20] Fama, Eugene and Kenneth French (2004), The capital asset pricing model: Theory and evidence, Journal of Economic Perspectives 18, 25-46.

[21] Hansen, Lars Peter and Kenneth Jand Singleton (1983), Stochastic consumption, risk aversion and the temporal behavior of asset returns, Journal of Political Economy 91, 249-268.

[22] Koubouros, Michail, Dimitrios Malliaropulos, and Ekaterini Panopoulou (2005), Long-run cash-flow and discount-rate risks in the cross-section of US returns, National University of Ireland, Maynooth, WP No1580505.

[23] Mehra, Rajnish and Edward Prescott (1985), The equity premium: A puzzle, Journal of Monetary Economics 15, 145-161 .

[24] McQueen, Grant, Michael Pinegar and Steven Thorley (1996), Delayed reaction to good news and the cross-autocorrelation of portfolio returns, Journal of Finance $51,889-919$

[25] Merton, Robert (1973), An intertemporal capital asset pricing model, Econometrica $41,867-887$.

[26] Peterson, James and Gary Sanger (1995), Cross-autocorrelations, systematic risk and the period of listing, unpublished paper, University of Notre Dame.

[27] Phylaktis, Kate and Fabiola Ravazzolo (2002), Measuring financial and economic integration with equity prices in emerging markets, Journal of International Money and Finance 21, 879-903 .

[28] Rozeff, Michael (1984), Dividend yields are equity risk premiums, Journal of Portfolio Management 10, 68-75.

[29] Scholes, Myron and Joseph Williams (1977), Estimating betas from nonsynchronous data, Journal of Financial Economics 5, 309-327. 
[30] Weil, Philippe (1989), The equity premium puzzle and the riskfree rate puzzle, Journal of Monetary Economics 24, 401-421 
Table 1. VAR estimates for market portfolio

\begin{tabular}{ccccc}
\hline \hline & $r_{m, t+1}$ & $\Delta \log \left(L I_{t+1}\right)$ & $p_{t+1}-e_{t+1}$ & $V S_{t+1}$ \\
\hline constant & -0.033 & 0.023 & 0.055 & -0.032 \\
& $(0.021)$ & $(0.009)$ & $(0.029)$ & $(0.041)$ \\
$r_{m, t}$ & 0.147 & -0.056 & 0.043 & -0.185 \\
$\Delta \log \left(L I_{t}\right)$ & $(0.086)$ & $(0.039)$ & $(0.119)$ & $(0.165)$ \\
& 0.194 & 0.528 & -0.077 & 0.405 \\
$p_{t}-e_{t}$ & $0.160)$ & $(0.073)$ & $(0.223)$ & $(0.308)$ \\
& $(0.015)$ & -0.011 & 0.969 & 0.044 \\
$V S_{t}$ & 0.036 & $-0.007)$ & $(0.021)$ & $(0.028)$ \\
& $(0.006)$ & $(0.006)$ & -0.034 & 0.967 \\
$R^{2}$ & $9.5 \%$ & $32.9 \%$ & $9.018)$ & $(0.025)$ \\
$F$-stat. & 3.530 & 16.499 & 598.4 & $91.9 \%$ \\
LM Test for Heteroscedasticity $(\mathrm{ARCH} \mathrm{Test:} \operatorname{lag}=4)$ \\
\cline { 2 - 5 } & $\hat{u}_{r_{W}}$ & $\hat{u}_{\Delta \log (L I)}$ & $\hat{u}_{p-e}$ & $\hat{u}_{V S}$ \\
\cline { 2 - 5 }$F$-stat. & 0.327 & 1.081 & 2.134 & 0.709 \\
$p$-value & {$[0.859]$} & {$[0.369]$} & {$[0.080]$} & {$[0.593]$} \\
\hline \hline
\end{tabular}

Table 2: Market portfolio cash-flow and discount-rate news

\begin{tabular}{cccccc}
\hline \hline & \multicolumn{2}{c}{ Covariance matrix of news } & & \multicolumn{2}{c}{ News corr/st.d. } \\
\hline & $N_{M}^{C F}$ & $N_{M}^{D R}$ & & $N_{M}^{C F}$ & $N_{M}^{D R}$ \\
\hline$N_{M}^{C F}$ & 0.0081 & 0.0034 & $N_{M}^{C}$ & 0.091 & 0.563 \\
$N_{M}^{D R}$ & 0.0034 & 0.0046 & $N_{M}^{D}$ & 0.563 & 0.215 \\
\hline & Correlations of innovations with news & & \multicolumn{2}{c}{ Functions } \\
\hline Innovations/News & $N_{m}^{C F}$ & $N_{m}^{D R}$ & & $N_{M}^{C F}$ & $N_{M}^{D R}$ \\
\hline$r_{M}$ & 0.679 & -0.225 & $r_{M}$ shock & 1.052 & 0.052 \\
$\Delta \log (L I)$ & 0.277 & 0.295 & $\Delta \log (L I)$ shock & 0.683 & 0.683 \\
$p-e$ & -0.224 & 0.398 & $p-e$ shock & 0.273 & 0.273 \\
$V S$ & 0.603 & 0.855 & $V S$ shock & 0.399 & 0.399 \\
\hline \hline
\end{tabular}


Table 3. Summary statistics

\begin{tabular}{|c|c|c|c|c|c|c|c|c|}
\hline Portfolio & Mean & St.Dev & $\rho_{1}$ & $\rho_{2}$ & $\rho_{3}$ & $\rho_{6}$ & $\rho_{9}$ & $\rho_{12}$ \\
\hline \multicolumn{9}{|c|}{ Market portfolio } \\
\hline & 9.85 & 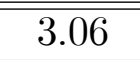 & 0.13 & 0.08 & 0.06 & 0.05 & -0.11 & -0.05 \\
\hline \multicolumn{9}{|c|}{ Panel A. Book-to-market Portfolios } \\
\hline High & $\overline{16.07}$ & 3.67 & 0.12 & 0.01 & 0.16 & 0.12 & -0.10 & 0.02 \\
\hline 2 & 8.16 & 3.42 & 0.19 & 0.09 & 0.07 & 0.03 & -0.13 & -0.06 \\
\hline 3 & 9.99 & 3.44 & 0.16 & 0.14 & -0.02 & 0.07 & -0.15 & 0.00 \\
\hline 4 & 5.63 & 3.30 & 0.13 & 0.16 & 0.09 & 0.00 & -0.03 & -0.07 \\
\hline Low & 8.59 & 3.25 & 0.15 & 0.06 & 0.04 & 0.05 & -0.01 & -0.10 \\
\hline \multicolumn{9}{|c|}{$\begin{array}{c}\text { Panel B. Dividend-Yield Portfolios } \\
\end{array}$} \\
\hline High & 13.62 & 2.96 & 0.07 & 0.02 & 0.06 & 0.05 & -0.17 & -0.02 \\
\hline 2 & 6.05 & 3.47 & 0.11 & 0.15 & 0.00 & 0.06 & -0.13 & 0.06 \\
\hline 3 & 9.40 & 3.39 & 0.18 & 0.11 & 0.01 & 0.00 & -0.06 & -0.09 \\
\hline 4 & 8.25 & 3.44 & 0.15 & 0.09 & 0.15 & 0.05 & -0.06 & -0.08 \\
\hline Low & 6.13 & 3.50 & 0.16 & 0.22 & 0.05 & 0.06 & -0.11 & -0.08 \\
\hline \multicolumn{9}{|c|}{ "Panel C. Size Portfolios } \\
\hline Large & 9.08 & 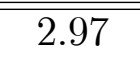 & 0.10 & 0.02 & 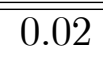 & 0.04 & -0.15 & -0.02 \\
\hline 2 & 9.05 & 3.69 & 0.19 & 0.19 & 0.16 & 0.09 & 0.03 & -0.03 \\
\hline 3 & 14.68 & 4.09 & 0.26 & 0.17 & 0.19 & 0.07 & 0.03 & -0.07 \\
\hline 4 & 16.28 & 4.33 & 0.25 & 0.23 & 0.25 & 0.13 & 0.05 & -0.05 \\
\hline Small & 34.27 & 5.02 & 0.27 & 0.26 & 0.27 & 0.15 & 0.08 & -0.15 \\
\hline \multicolumn{9}{|c|}{ Panel D. Price-to-Earnings Portfolios } \\
\hline High & 5.53 & 3.89 & 0.24 & 0.14 & 0.08 & -0.03 & -0.02 & -0.12 \\
\hline 2 & 6.60 & 3.53 & 0.17 & 0.11 & 0.04 & 0.06 & 0.00 & -0.06 \\
\hline 3 & 10.19 & 3.37 & 0.18 & 0.24 & 0.08 & 0.11 & -0.10 & -0.04 \\
\hline 4 & 9.32 & 2.99 & 0.13 & 0.10 & -0.01 & 0.11 & -0.11 & 0.02 \\
\hline Low & 19.80 & 3.05 & 0.13 & 0.07 & 0.03 & 0.14 & -0.10 & 0.03 \\
\hline \multicolumn{9}{|c|}{ Panel E. 3-Month Momentum Portfolios } \\
\hline Winners & 17.78 & 3.37 & 0.28 & 0.22 & 0.19 & 0.11 & -0.11 & -0.06 \\
\hline 2 & 13.84 & 3.52 & 0.09 & 0.12 & 0.10 & 0.10 & -0.15 & -0.10 \\
\hline 3 & 13.70 & 3.56 & 0.21 & 0.22 & 0.09 & 0.06 & -0.01 & -0.03 \\
\hline 4 & 5.26 & 3.71 & 0.10 & 0.08 & 0.01 & 0.03 & 0.06 & -0.09 \\
\hline Losers & 3.01 & 4.03 & 0.04 & 0.04 & 0.01 & 0.08 & -0.06 & 0.01 \\
\hline
\end{tabular}


Table 4. CAPM, Cash-flow, discount-rates, HML and SMB betas

\begin{tabular}{|c|c|c|c|c|c|c|c|c|c|c|}
\hline \multicolumn{11}{|c|}{ Panel A. Book-to-market portfolios } \\
\hline & $\widehat{\beta}_{i, m}$ & s.e. & $\widehat{\beta}_{i, C F}$ & s.e.. & $\widehat{\beta}_{i, D R}$ & s.e. & $\widehat{\beta}_{i, H M L}$ & s.e. & $\widehat{\beta}_{i, S M B}$ & s.e. \\
\hline High & 1.445 & 0.222 & 0.760 & 0.131 & 0.685 & 0.235 & -0.185 & 0.246 & 0.364 & $\overline{0.243}$ \\
\hline 2 & 1.300 & 0.216 & 0.714 & 0.149 & 0.586 & 0.253 & -0.189 & 0.218 & 0.224 & 0.205 \\
\hline 3 & 1.170 & 0.196 & 0.706 & 0.162 & 0.464 & 0.226 & 0.038 & 0.233 & 0.140 & 0.224 \\
\hline 4 & 1.183 & 0.218 & 0.621 & 0.122 & 0.562 & 0.235 & 0.244 & 0.245 & 0.027 & 0.190 \\
\hline Low & 0.893 & 0.212 & 0.479 & 0.124 & 0.414 & 0.232 & 0.374 & 0.210 & 0.077 & 0.195 \\
\hline \multicolumn{11}{|c|}{ Panel B. Dividend-yield portfolios } \\
\hline & $\widehat{\beta}_{i, m}$ & s.e. & $\widehat{\beta}_{i, C F}$ & s.e.. & $\widehat{\beta}_{i, D R}$ & s.e. & $\widehat{\beta}_{i, H M L}$ & s.e. & $\widehat{\beta}_{i, S M B}$ & s.e. \\
\hline High & 1.025 & 0.156 & 0.684 & 0.132 & 0.341 & 0.186 & -0.177 & 0.154 & -0.030 & 0.163 \\
\hline 2 & 1.046 & 0.217 & 0.633 & 0.185 & 0.412 & 0.240 & -0.115 & 0.232 & 0.022 & 0.209 \\
\hline 3 & 1.270 & 0.240 & 0.681 & 0.135 & 0.589 & 0.257 & 0.274 & 0.239 & 0.005 & 0.199 \\
\hline 4 & 1.102 & 0.262 & 0.526 & 0.122 & 0.576 & 0.258 & 0.351 & 0.232 & 0.379 & 0.221 \\
\hline Low & 1.170 & 0.272 & 0.577 & 0.151 & 0.593 & 0.241 & 0.346 & 0.228 & 0.251 & 0.227 \\
\hline \multicolumn{11}{|c|}{ Panel C. Size portfolios } \\
\hline & $\widehat{\beta}_{i, m}$ & s.e. & $\widehat{\beta}_{i, C F}$ & s.e.. & $\widehat{\widehat{\beta}}_{i, D R}$ & s.e. & $\widehat{\beta}_{i, H M L}$ & s.e. & $\widehat{\beta}_{i, S M B}$ & s.e. \\
\hline Large & 0.850 & 0.141 & 0.608 & 0.107 & 0.242 & 0.190 & 0.037 & 0.155 & -0.198 & 0.188 \\
\hline 2 & 1.474 & 0.312 & 0.641 & 0.171 & 0.834 & 0.279 & 0.151 & 0.288 & 0.572 & 0.203 \\
\hline 3 & 1.713 & 0.372 & 0.632 & 0.183 & 1.081 & 0.301 & 0.103 & 0.342 & 1.025 & 0.220 \\
\hline 4 & 1.833 & 0.398 & 0.648 & 0.171 & 1.185 & 0.307 & 0.233 & 0.352 & 1.434 & 0.238 \\
\hline Small & 2.275 & 0.517 & 0.714 & 0.234 & 1.561 & 0.363 & 0.154 & 0.430 & 1.764 & 0.308 \\
\hline \multicolumn{11}{|c|}{ Panel D. Price-to-earnings portfolios } \\
\hline & $\widehat{\beta}_{i, m}$ & s.e. & $\widehat{\beta}_{i, C F}$ & s.e.. & $\widehat{\beta}_{i, D R}$ & s.e. & $\widehat{\beta}_{i, H M L}$ & s.e. & $\widehat{\beta}_{i, S M B}$ & s.e. \\
\hline High & 1.364 & 0.287 & 0.658 & 0.163 & 0.706 & 0.275 & 0.518 & 0.296 & 0.402 & 0.220 \\
\hline 2 & 1.178 & 0.194 & 0.624 & 0.128 & 0.554 & 0.227 & 0.287 & 0.237 & 0.115 & 0.225 \\
\hline 3 & 1.150 & 0.245 & 0.625 & 0.156 & 0.525 & 0.265 & 0.025 & 0.218 & 0.230 & 0.217 \\
\hline 4 & 1.024 & 0.176 & 0.610 & 0.138 & 0.414 & 0.188 & -0.062 & 0.177 & -0.018 & 0.170 \\
\hline Low & 1.025 & 0.194 & 0.730 & 0.173 & 0.296 & 0.215 & -0.029 & 0.167 & 0.070 & 0.150 \\
\hline \multicolumn{11}{|c|}{ Panel E. 3-month momentum } \\
\hline & $\widehat{\beta}_{i, m}$ & s.e. & $\widehat{\widehat{\beta_{i, C F}}}$ & s.e.. & $\overline{\widehat{\beta}_{i, D R}}$ & s.e. & $\widehat{\beta}_{i, H M L}$ & s.e. & $\widehat{\beta}_{i, S M B}$ & s.e. \\
\hline Winners & 1.338 & 0.348 & 0.699 & 0.151 & 0.639 & 0.340 & 0.299 & 0.224 & 0.539 & 0.261 \\
\hline 2 & 1.081 & 0.288 & 0.526 & 0.111 & 0.555 & 0.294 & 0.214 & 0.224 & 0.385 & 0.245 \\
\hline 3 & 1.324 & 0.328 & 0.678 & 0.152 & 0.646 & 0.315 & 0.251 & 0.247 & 0.432 & 0.200 \\
\hline 4 & 1.213 & 0.236 & 0.518 & 0.166 & 0.696 & 0.253 & 0.040 & 0.301 & 0.241 & 0.193 \\
\hline Losers & 1.101 & 0.248 & 0.424 & 0.163 & 0.677 & 0.249 & -0.159 & 0.341 & 0.077 & 0.176 \\
\hline
\end{tabular}


Table 5. Cross-sectional Asset Pricing Tests

\begin{tabular}{|c|c|c|c|c|c|c|}
\hline & CAPM & Two-Beta & $\overline{\mathrm{CF}}$ & $\overline{\mathrm{DR}}$ & Fama-French & All \\
\hline$\lambda_{0}$ & $\begin{array}{c}-0.005 \\
(0.0048)\end{array}$ & $\begin{array}{c}-0.0139^{* *} \\
(0.0062)\end{array}$ & $\begin{array}{l}-0.0107 \\
(0.0065)\end{array}$ & $\begin{array}{c}0.0026 \\
(0.0031)\end{array}$ & $\begin{array}{c}0.0088 \\
(0.0072)\end{array}$ & $\begin{array}{c}0.0025 \\
(0.0070)\end{array}$ \\
\hline$\lambda_{m}$ & $\begin{array}{c}0.0115^{* * *} \\
(0.0038)\end{array}$ & & & & $\begin{array}{l}-0.0015 \\
(0.0064)\end{array}$ & \\
\hline$\lambda_{C F}$ & & $\begin{array}{c}0.0274^{* * *} \\
(0.0093)\end{array}$ & $\begin{array}{c}0.0320^{* * *} \\
(0.0113)\end{array}$ & & & $\begin{array}{l}0.0166^{* *} \\
(0.0076)\end{array}$ \\
\hline$\lambda_{D R}$ & & $\begin{array}{l}0.0096^{* *} \\
(0.0043)\end{array}$ & & $\begin{array}{l}0.0107^{* *} \\
(0.0051)\end{array}$ & & $\begin{array}{l}-0.0132 \\
(0.0082)\end{array}$ \\
\hline$\lambda_{H M L}$ & & & & & $\begin{array}{c}-0.0066^{*} \\
(0.0036)\end{array}$ & $\begin{array}{c}-0.0051 \\
(0.0032)\end{array}$ \\
\hline$\lambda_{S M B}$ & & & & & $\begin{array}{l}0.0098^{* *} \\
(0.0044)\end{array}$ & $\begin{array}{c}0.0159^{* * *} \\
(0.0054)\end{array}$ \\
\hline $\operatorname{adj} .-R^{2}$ & $42.2 \%$ & $\begin{array}{c}46.6 \% \\
28577^{* * * *}\end{array}$ & $21.5 \%$ & $30.4 \%$ & $48.5 \%$ & $62.6 \%$ \\
\hline$\gamma$ & & $(0.1612)$ & & & & \\
\hline$\lambda$ & & $\begin{array}{c}0.0096 \\
(0.0043)\end{array}$ & & & & \\
\hline
\end{tabular}


Figure 1. Fitted vs. Realized Average Returns: CAPM

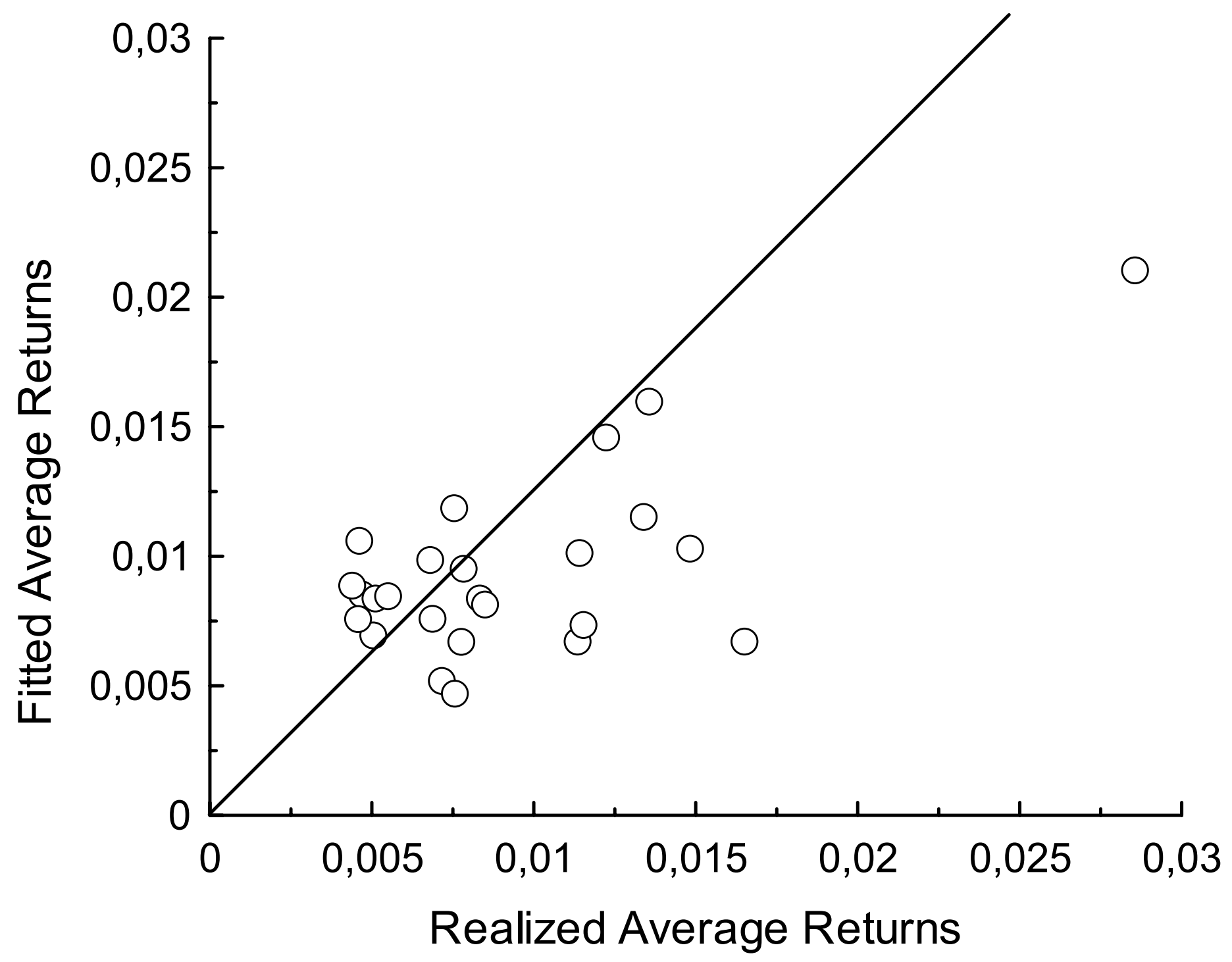


Figure 2. Fitted vs. Realized Average Returns: Unrestricted Two-Beta ICAPM

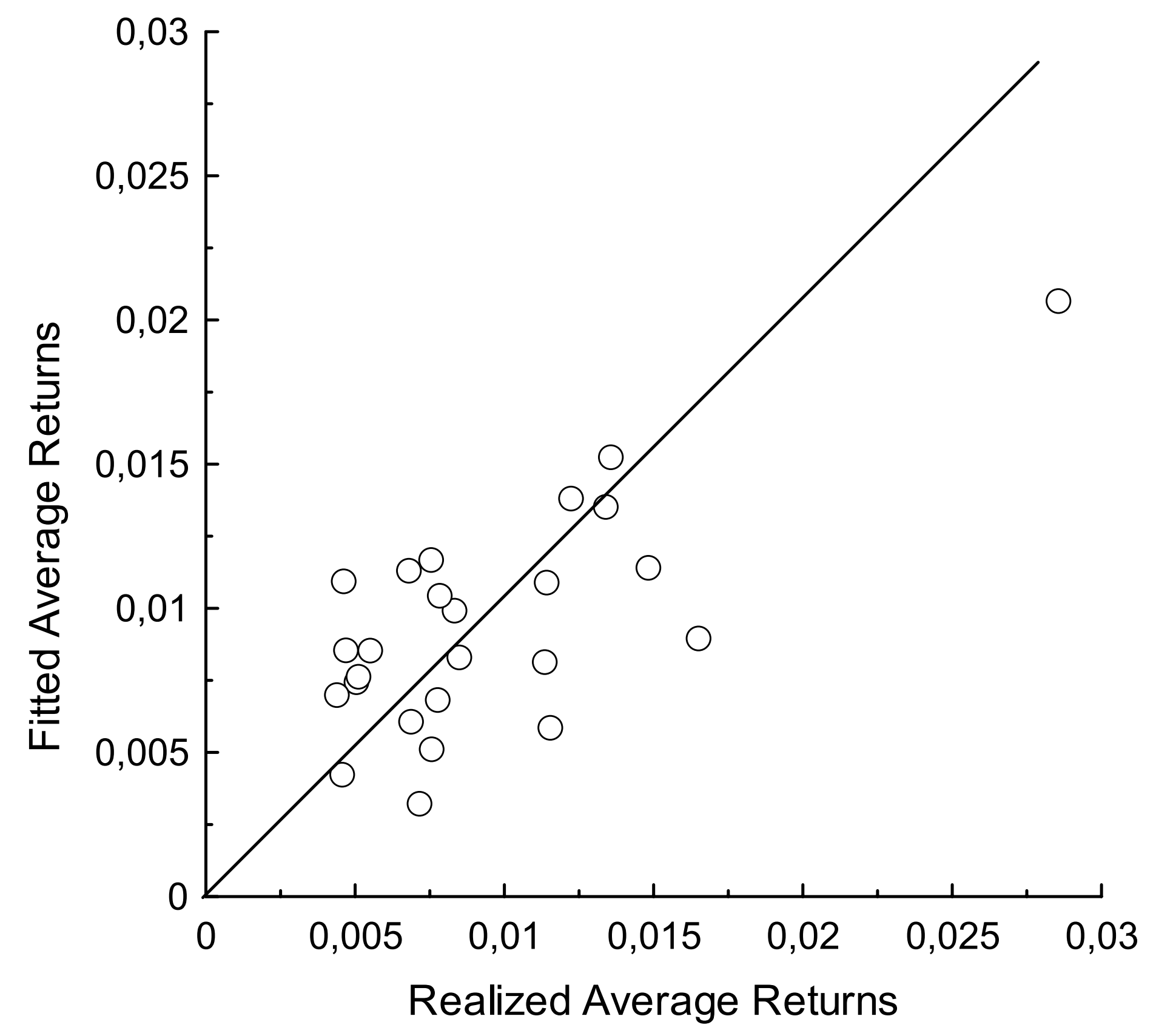


Figure 3. Fitted vs. Realized Average Returns: Restricted Two-Beta ICAPM

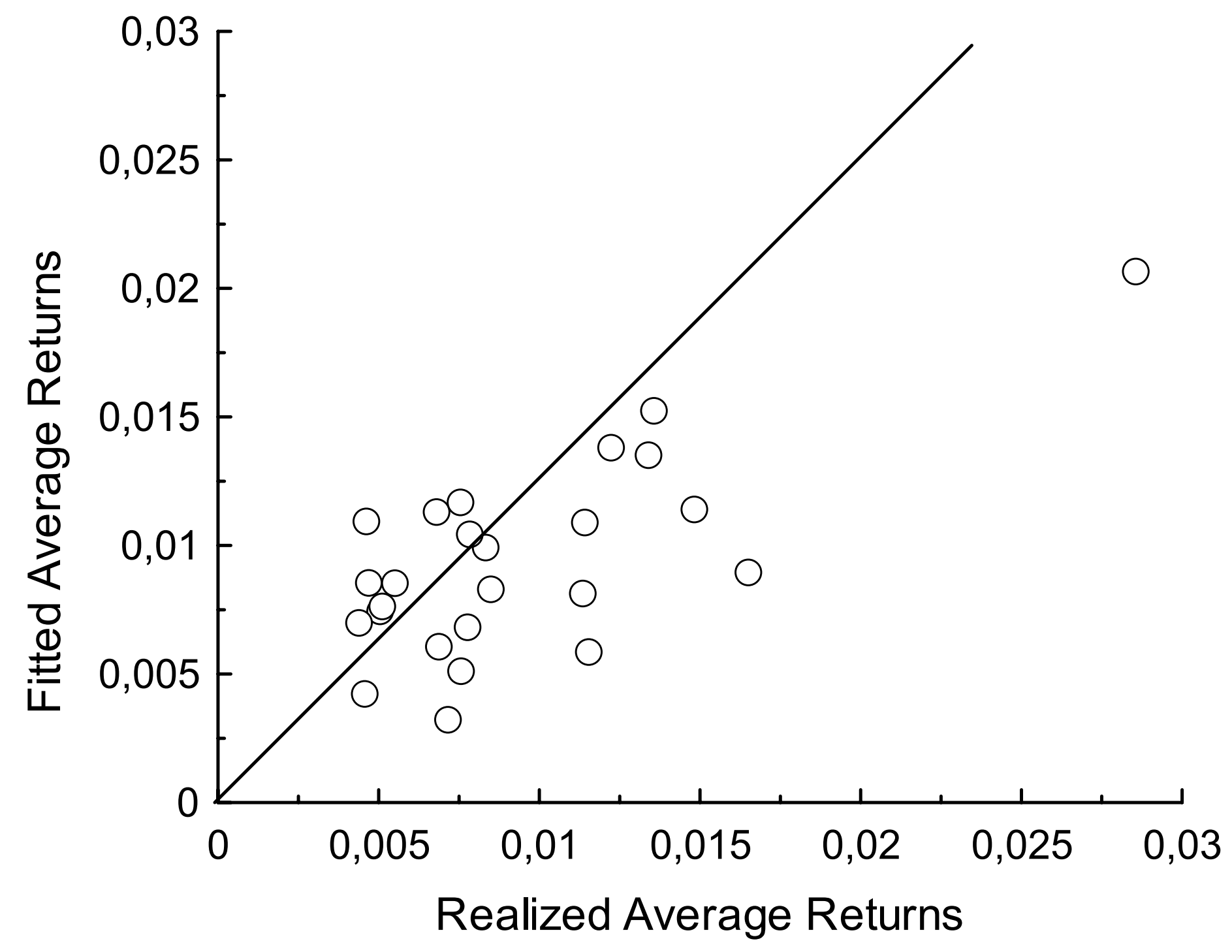


Figure 4. Fitted vs. Realized Average Returns: Fama-French (1993)

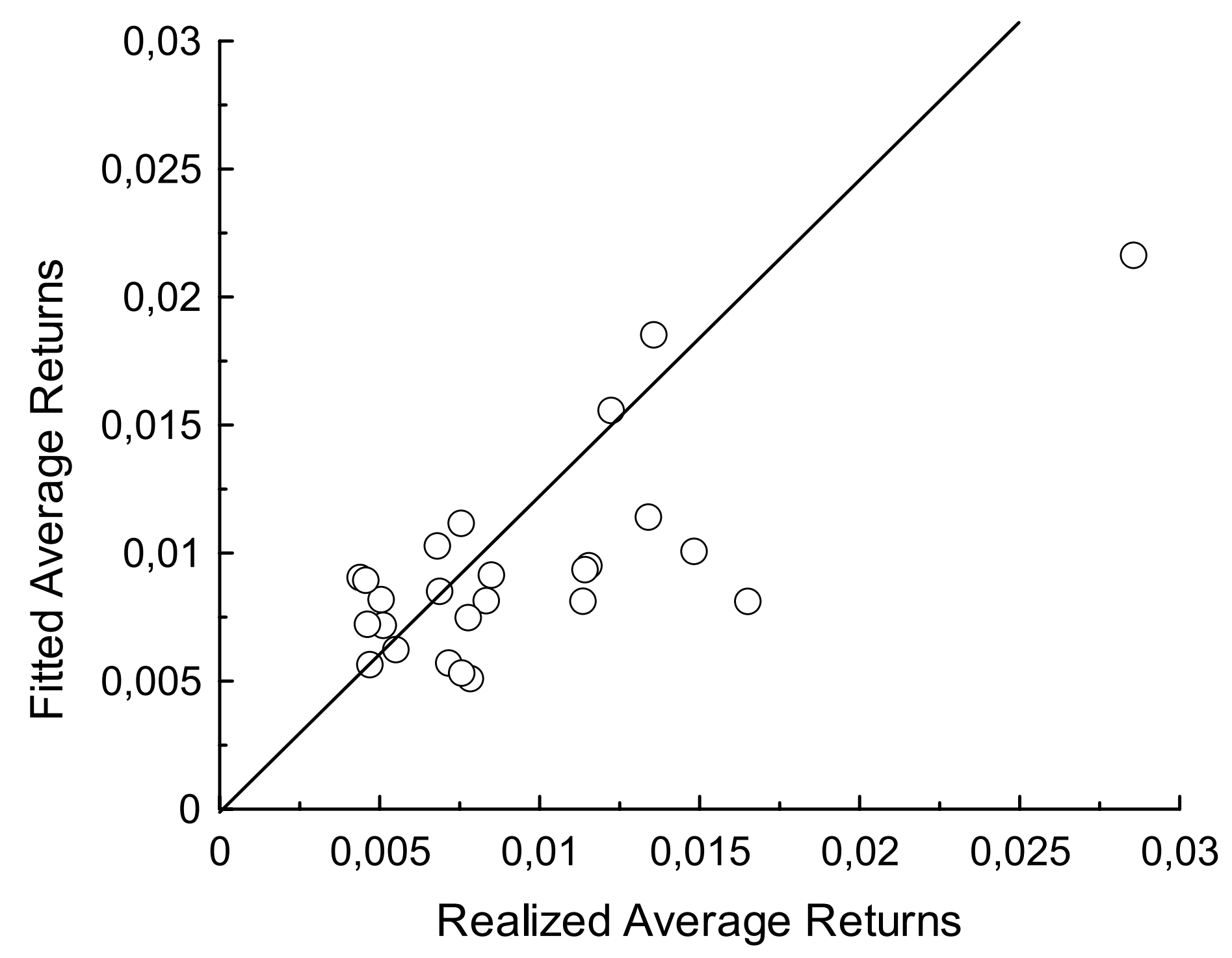

